International Journal of Philosophy and Theology

December 2014, Vol. 2, No. 4, pp. 61-68

ISSN: 2333-5750 (Print), 2333-5769 (0 nline)

Copyright ( $\odot$ The Author(s). 2014. All Rights Reserved.

Published by American Research Institute for Policy D evelopment

DO I: $10.15640 /$ ijpt.v2n4a4

URL: http:/ / dx.doi.org/ 10.15640/ ijpt.v2n4a4

\title{
Is Hume's Account of the Soul Contradictory?
}

\author{
Alan Schwerin ${ }^{1}$
}

\begin{abstract}
In his Treatise of Human Nature Hume argues for a provocative account of the soul; the soul - or self, as he prefers to call it - is nothing but a bundle of perceptions. But this bold thesis, concedes Hume, gives rise to a predicament concerning two incompatible propositions, or principles as he calls them: one on the nature of perceptions, the other on the capabilities of the mind: "In short, there are two principles, which I cannot render consistent; nor is it in my power to renounce either of them, viz. that all our distinct perceptions are distinct existences, and that the mind never perceives any real connexion among distinct existences". But the situation is not hopeless, thinks Hume. Someone might be able to show that these principles are actually consistent: "O thers, perhaps, or myself, upon more mature reflection, may discover some hypothesis, that will reconcile those contradictions". (Treatise 636, my emphasis) My paper is an attempt to throw light on this important component in Hume's analysis of his account of the self. In the course of our investigation of Hume's suggestion that an hypothesis can resolve his contradiction we will learn more about his conception of a contradiction ultimately enriching our understanding of his account of the soul.
\end{abstract}

Keywords: soul, self, contradiction, labyrinth, perception, bundle theory, ontology

Towards the end of his Treatise of Human Nature David Hume expresses serious reservations about the standing of his innovative account of the soul. As he sees it, the bold account of the soul - or self, as he prefers to call it, that he so confidently outlines in his 1739 magnumqus is seriously defective, driving him into a labyrinth.

\footnotetext{
${ }^{1} \mathrm{PhD}$, Associate Professor of Philosophy, D epartment of Philosophy, Monmouth University
} 
In the appendix to the TreatiseHume suggests that the predicament that he is in where his account of the self is concerned can be traced to two incompatible propositions, or principles as he calls them: one on the nature of perceptions, the other on the capabilities of the mind.

In short, there are two principles, which I cannot render consistent; nor is it in my power to renounce either of them, viz. that all our distinct perceptions are distinct existences, and that the mind never perceives any real connexion among distinct existences.(Treatise636, Hume's emphasis)

But the situation is not hopeless, thinks Hume. Someone might be able to show that these principles are actually consistent, and accordingly, dissolve the labyrinth: "Others, perhaps, or myself, upon more mature reflection, may discover some hypothesis, that will reconcile those contradictions". (Treatise636, my emphasis) This suggestion is intriguing. The assumption that an additional proposition is able to "reconcile those contradictions", thereby dissolving his labyrinth, calls for closer attention. In my analysis I shall throw light on this important component of Hume's assessment of his account of the self. In the course of the investigation of Hume's suggestion that an hypothesis can resolve his contradiction we will learn more about his conception of a contradiction - ultimately enriching our understanding of his account of the soul.

It is important to notice from the outset that the two propositions that Hume has singled out for consideration are different. This poses a serious problem for Hume's assertion that two of the major principles in his account of the self involve a contradiction that hopefully someone will be able to solve. Let ' $\mathrm{A}$ ' represent the first principle and ' $\mathrm{B}$ ' the second. With this representation it does not follow that the conjunction of the two principles entails a contradiction. To put it more pointedly, we can show formally that the adoption of these different propositions, on their own, cannot entail a contradiction:

$$
\begin{array}{lll}
\text { 1. } & \mathrm{A} & \\
\text { 2. } & \mathrm{B} & / \Delta \sim(\mathrm{A} . \mathrm{B})
\end{array}
$$

This reasoning is invalid as it stands. The suggestion that two propositions contradict each other amounts to the proposal that they are mutually exclusive: if the one proposition is true, the other must be false. 
The assertion of the one proposition strictly entails the denial of the other. They certainly cannot have similar truth-values. Of course, this is to assume that the law of excluded middle is correct, and nothing in Hume's analysis suggests that this fundamental requirement must be set aside or even rejected. When Hume claims that two of his major theses in his account of the self are contradictory, it therefore seems reasonable to assume, I suggest, that he is not using 'contradiction' in the strict traditional sense outlined here.

So perhaps Hume in the appendix to the Treatiseis using 'contradiction' in a non-traditional sense. That this is a plausible interpretation of his understanding of a contradiction is strengthened when we take into account his later suggestion about a third proposition serving as a means to reconcile the apparent contradiction. As I understand the traditional conception of a contradiction, propositions in a contradictory state of affairs cannt be reconciled i.e. they are logically incompatible. What then does Hume mean when he uses the word 'reconcile'? Unfortunately for us, he does not explain this important term in the appendix. Nor does he elaborate on this term in his discussion of personal identity in the main section of the Treatise So we are on our own. But we are not completely at sea, for Hume does provide us with some interesting material in the appendix that we can use to construct a workable Humean understanding of the term.

\section{Section One: H ume on 'Reconcile'}

When Hume declares that he is in a quandary, unable to 'render consistent' the two principles that he views as contradictions, he singles out a state of affairs that in his opinion could rescue the day:

Did our perceptions either inhere in something simple and individual, or did the mind perceive some real connexion among them, there wou'd be no difficulty in the case. (Treatise636)

If only humans were more capable or the world of perceptions different, we could resolve the conflict that bedevils the Treatise account of the self. More specifically if perceptions were supported by a substance - presumably an indivisible self, or soul - or if the mind could discern the connections alleged to exist between our perceptions, the problem alluded to by Hume in the appendix would disappear. 
That is to say, there would be no inconsistency between the two principles that form the basis of his account of the self. Reality, unfortunately, being what it is, the inconsistency persists:

But no connexions among distinct existences are ever discoverable by human understanding. We only feel a connexion or a determination of the thought, to pass from one object to another. (Treatise635, Hume's emphasis)

However, precisely how would a change to the reality that Hume outlines, or even the adoption of a different reality or ontology, resolve the contradiction that allegedly compromises the two principles central to his account of the self? For that matter, can Hume's idealized world solve his problem?

At first blush it seems that alterations to reality, or perhaps the adoption of a different ontology, cannot solve Hume's problem. Was his not a problem about the incompatibility or inconsistency of propositions or principles? But propositions, in an important sense, are not in the world - they are apart from it, and possibly about the world and its constituents. Propositions occupy a realm different to that occupied by the constituents of the world. So precisely how can a change in the world resolve the logical or linguistic problem that Hume is referring to in the appendix? Hume does not tell us in any direct manner, unfortunately. But there are interesting hints in the Treatisethat might prove useful.

I think that an answer lies buried in the appendix. Immediately after outlining an idealized world that he suggests can resolve the problem of the inconsistent principles, Hume informs us of a second way out of the labyrinth that has entrapped him. As he sees it, the discovery of a suitable hypothesis also enables us to settle the matter:

Others, perhaps or myself, upon more mature reflection, may discover some hypothesis, that will reconcile those contradictions. (Treatise636, my emphasis)

If we can show that two propositions that appear to be irreconcilable are actually not as dissonant as we thought, we will be in the position to remove the contradiction. The reconciliation will need to reduce, and possibly completely eliminate the discrepancy between the two propositions. Hume offers a method to do just this. Early in the appendix he presents a semantic principle that enables philosophers and the vulgar to converse with each other even though their respective world views differ dramatically. 
This semantic principle holds the key to my question above on the relevance of changes to one's ontology to problems that are logical or linguistic. We need to consider this principle in a little detail.

\section{Section Two: On Hume's Semantic Principle}

In his writings Hume makes much of the disparity between philosophers and the uneducated vulgar. The appendix reflections from the Treatise on problems with his account of the self provides him with yet another opportunity to explore this issue. As Hume sees it, philosophers and the vulgar can be regarded as individuals locked in an intractable conflict about their respective accounts of reality. The vulgar confidently assert that there are physical objects, such as chimneys and chairs, for instance, while the philosophers are more circumspect and insist on the existence of discrete perceptions. These radically different conceptions of reality suggest that this is an irreconcilable conflict, and that there is a contradiction between their worlds. The discrepancy between these two world views seems to be so significant that the affirmation of the one perspective appears to entail the negation of the other. But in the appendix Hume suggests that a bridge can be erected between these rival perspectives. As he sees it, while each of the competing worlds is legitimate in its own right, or without internal conflict - for there is no contradiction within that world these fundamentally different worlds can and need to be reconciled, or brought into alignment, if the adherents of these different perspectives are to understand each other. Giving priority to the philosopher, Hume suggests that a semantic principle must be found that shows how to reconcile propositions about physical objects with propositions on perceptions:

...no proposition can be intelligible or consistent with regard to objects, which is not so with regard to perceptions. (Treatise634)

Each of these worlds can be successfully understood and described by their respective proponents. Accompanying these consistent - i.e. logically harmonious worlds there are consistent sets of symbols to refer to these worlds and their contents. The world of the philosopher, with its emphasis on perceptions, for instance, does not involve contradictions:

All perceptions are distinct. They are, therefore, distinguishable, and separable, and may be conceiv'd as separately existent, and may exist separately, without any contradiction or absurdity. (Treatise634) 
But the world of the vulgar is equally free of tension or ontological conflict:

But this table, which is present to me, and that chimney, may and do exist separately. This is the doctrine of the vulgar, and implies no contradiction. (Treatise 634)

However, the discourse of the vulgar, with its references to physical objects, will remain meaningless unless these expressions can be shown to be co-extensive with those of the philosophers. Only those claims about non-perceptions that can be rewritten as claims about perceptions can be understood.

For Hume, the philosopher's world of perceptions is the touchstone of intelligibility. Hence any proposition that is not about a perception must be trandatable into one about perceptions if that proposition is to be regarded as intelligible. It is the educated philosopher after determined that the competing discourses entail competing ontological commitments, who will be able to reconcile the different worlds. But it is important to recognize that the reconciliation will be conducted on the philosophers' terms. This is not a democratic process with some give or take from both sides of the issues. No. It is an unequal process - an asymmetrical procedurewith priority given to the philosophers' conception of reality. In this way the apparent discrepancies between the world of the philosopher and that of the vulgar can be minimized. With their semantic principles outlining the relationship between perceptions and physical objects the philosophers will be able to relate the two worlds.

In short, the philosopher will be able to reconcile the fundamentally different worlds of perceptions and physical objects. The conflict, or contradiction, to use Hume's terminology, can therefore be reconciled.

All of which suggests that Hume's proposal to reconcile the two major principles of his account of the self amounts to the proposal to formulate a semantic principle that enables investigators to relate the world of the vulgar to that of the philosopher. This semantic principle will function as a speculative proposition, or hypothesis, to explicitly connect worlds that might appear to be essentially unrelated to each other. What initially appears to be an irredeemable conflict, or contradiction, turns out to be an illusion that can be eliminated with appropriate ingenuity and equipment. The tool that is needed is an appropriate semantic principle, or hypothesis to bridge the world of physical objects with that of perceptions. All that remains is for the philosopher to formulate it and to put it to use. 
This helps explain Hume's optimism at the end of the appendix. After outlining the fundamental problem with his account of the self - a problem that on the surface appears to be so serious that he refers to it as a contradiction - he ends on a somewhat positive note. Not wanting to conclude his discussion with the suggestion that the fundamental problem will never be solved, as we have seen, Hume says this:

I pretend not, however, to pronounce it absolutely insuperable. Others, perhaps, or myself, upon more mature reflection, may discover some hypothesis, that will reconcile those contradictions. (Treatise636)

In his eyes, the situation is not hopeless. His provocative account of the self, for all its problems, can be saved. A compromise can be found to reconcile what appear to be two irreconcilable propositions.

This suggests an interesting view on language. Principles or propositions, for Hume, are not dissimilar to human beings in that they possess a range of properties and manifest various relationships with each other that can be studied, altered or possibly even manipulated. For instance, individual human beings display various levels of integrity. They possess various moral characteristics; some people are good, some are bad, some happy, some depressed, and so on.

By the same token propositions also possess attributes that can be identified and studied; some propositions are true, some false, some obscure, some clear, some intelligible, some unintelligible, and so on. And as with human beings, propositions are often related to each other. On occasion the relationship is amicable, on occasion it is tempestuous. When two propositions conflict with each other the tension between them might reach such a level as to warrant the use of the term 'contradiction'. This appears to be Hume's assessment of the relationship between the two principles central to his account of the self. So, while one might be tempted to conclude that nothing can be done to smooth over the discrepancies between the two foundational principles that his account of the self rests on, we need not take this course of action. As I have shown in my analysis above, we can preempt this defeatist attitude. For the tension or contradiction can be eliminated - provided that a working hypothesis, or semantic principle is found that connects the two rival principles that underscore Hume's account of the self. 
However, might there be more to the problem of reconciliation than meets Hume's eyes? Surely the attempt to reconcile the philosopher and the vulgar, with their respective ontologies, is unlikely to be problem free. Consider what happens when one attempts to reconcile competing world views. When we seek to reconcile two individuals - perhaps two brothers who are angry with each other - we strive to establish peace between them - assisting them to bury the hatchet. Where there was a conflict in the past over a specific issue, we hopefully now have some agreement: an attempt has been made to alter the relationship between the two in order to establish harmony where previously there was unrest. While the act of reconciliation has helped to reduce the distance between the two brothers, it very likely has not removed the fundamental differences between the brothers. Sharp differences are bound to persist in the world views that brought about the conflict in the first place. But the world of the vulgar with his ontological commitments to physical objects is fundamentally different to that of the philosopher with her commitment to perceptions. Can these radically different worlds, their their respective languages, perspectives and values be reconciled? This intriguing issue on the commensurability of different world views with their respective linguistic frameworks cannot be dealt with here.

\section{References}

Bricke, John 1980 Humés Philosqphy of Mind Princeton University Press. Princeton, New Jersey

Fieser, James (Ed.) 2000 Early Responses to Humes Meaphysical and Epistemdogial Writings (Volumes Three and Four) Thoemmes Press, Bristol

Harrison, Jonathan 1976 Humes Moral EpistemdogyClarendon Press. Oxford

Hume, D avid 1974 Enquinies Coneming Human Undestanding and Conceming thePriniples of Morals (Ed. LA Selby-Bigge and PH Nidditch) Clarendon Press.

Oxford 1978 Treatise of Human Nature (Ed. LA Selby-Bigge and PH Nidditch) Clarendon Press. Oxford

Laird, John 1967 Humés Philosqphy of Human NatureArchon Books. London

Pears, D avid 1990 Humes System An Examination of theFirst Book of his TreatiseOxford University Press, New York

Stroud, Barry 1977 HumeRoutledge and Kegan Paul, London

Williams, Bernard 1973 Prdbens of theSef: Philosqphical Papes 1956 - 1972 Cambridge University Press, London

Winkler, Kenneth "All is revolution in us": Personal identity in Shaftesbury and Hume HumeStudies Volume XXVI, Number 1, pp 3 - 4 